\title{
EVOLUÇÃO DO VULCANISMO ALCALINO DA PORÇÃO SUL DO PLATÔ DO TAQUAREMBÓ, DOM PEDRITO-RS.
}

\begin{abstract}
THE ALKALINE VOLCANISM EVOLUTION OF THE TAQUAREMBÓ PLATEAU SOUTH PORTION, DOM PEDRITO, RS, BRAZIL The alkaline acid volcanism of the Southern part of the Taquarembo Plateau, Dom Pedritro, RS, is located at the Western portipn of the Sul-rio-grandense Shield. This Neo-Proterozoic unit, named Acampamento Velho Formation, is represented by effusive and pyroclastic rock succession, referred as Acid Volcanic Sequence (SVA). The volcanic activity was characterized by pulse successions, effusive and explosive, as registered by the presence of lava flows, flow and surge pyroclastic deposits. Re-worked volcanoclastic deposits, with abundant juvenile clasts and volcanogenic sedimentary rocks are also observed. The SVA stratigraphy shows an early trachytic followed by rhyolitic volcanism. Themain geochemieal characteristics of the SVA are the high values of $\mathrm{SiO}_{2}, \mathrm{FeO}_{t}, \mathrm{Na}_{2} \mathrm{O}, \mathrm{K}_{2} \mathrm{O}, \mathrm{Rb}, \mathrm{Zr}, \mathrm{Nb}, \mathrm{Y}, \mathrm{ETR}$, high $\mathrm{FeO}_{\mathrm{t}} / \mathrm{FeO}+\mathrm{MgO}$ ratio and low values of $\mathrm{Al}_{2} \mathrm{O}_{3}, \mathrm{MgO}, \mathrm{CaO}, \mathrm{Sr}$ and $\mathrm{Ba}$, which characterize this magmatism as of alkaline affinity and peralkaline character (comendiitic). The magmatic evolution was dominated by mineral fractionation, involving mainly plagioclase, alkali-feldspar, pyroxene and magnetite. The REE pattern and the tectonic environmental discriminants diagrams (e.g. $\mathrm{Nb}$ x Zr) classify this volcanism as typical post-orogenic magmatism, associated with the later stages of the Brasiliano Cycle at the Sul-rio-grandense Shield.

Keywords: rhyolites, petrology, Sul-rio-grandense Shield.

RESUMO O vulcanismo ácido alcalino da porção sul do Platô do Taquarembo, Dom Pedrito, RS está localizado na porção oeste do Escudo Sul-riograndense. Esta unidade Neoproterozóica é referida geralmente como Formação Acampamento Velho, sendo representada nesta região por uma sucessão de rochas efusivas, piroclásticas e vulcanoclásticas denominada Sequência Vulcânica Acida (SVA). A atividade vulcânica nesta região caracterizou-se por sucessivos pulsos efusivos e explosivos em ambiente subaéreo, diagnosticados pela presença de lavas, depósitos piroclásticos de fluxo e do tipo surge. Adicionalmente observa-se a presença de depósitos vulcanoclásticos ressedimentados, caracterizados pela presença abundante de clastos juvenis além de rochas sedimentares, caracterizadas pela mistura de clastos de rochas vulcânicas retrabalhadas. A estratigrafia dos derrames da SVA indica um vulcanismo inicial traquítico que grada para composicões riolíticas. As principais características geoquímicas da SVA são elevados teores de $\mathrm{SiO}_{2}, \mathrm{FeO}_{t}, \mathrm{Na}_{2} \mathrm{O}, \mathrm{K}_{2} \mathrm{O}, \mathrm{Rb}, \mathrm{Zr}, \mathrm{Nb}, \mathrm{Y}$, ETR, altas razões $\mathrm{FeO}_{t} / \mathrm{FeO}+\mathrm{MgO}$ e baixos valores para $\mathrm{Al}_{2} \mathrm{O}_{3}, \mathrm{MgO}, \mathrm{CaO}, \mathrm{Sr}$ e Ba que permitem caracterizar este magmatismo como de afinidade alcalina e caráter peralcalino (comendítico). A evolução deste magmatismo foi dominada por mecanismos de fracionamento mineral, envolvendo principalmente plagioclásio, feldspato alcalino, piroxênio e magnetita. $\mathrm{O}$ padrão mostrado pelo diagrama de elementos terra rara, bem como a utilização de diagramas discriminantes de ambiente tectônico (e.g. Nb x Zr), permitiram caracterizar este magmatismo como pós-orogênico, evidenciando assim as últimas manifestações do Ciclo Brasiliano no Escudo Sul-riograndense.
\end{abstract}

Palavras-chaves: riólitos, petrologia, Escudo Sul-rio-grandense.

INTRODUÇÃO $\mathrm{Na}$ estruturação e reconstrução dos grandes terrenos geológicos, uma importante ferramenta é a relação entre o vulcanismo e ambientes tectônicos, cujas características geoquímicas, definidas em diversas sucessões vulcânicas modernas, permitem a identificação de padrões geoquímicos característicos. Estes, aliados aos dados de campo, tais como tipo de associação vulcânica, faciologia e variações composicionais, auxiliam na reconstrução de terrenos geológicos antigos.

Este procedimento permitiu a organização do magmatismo relacionado ao Ciclo Brasiliano no Escudo Sul-rio-grandense, onde identificou-se uma sequência plutônica cálcio-alcalina, cuja idade é em torno de $700 \mathrm{Ma}$ (Kraemer 1995), sucedida por vulcanismo e plutonismo shoshonítico com cerca de $600 \mathrm{Ma}$ (Babinski et al. 1996) e por vulcanismo e plutonismo ácido alcalino de $580 \mathrm{Ma}$ (Leite 1995). A fração vulcânica deste último evento é bem representada na porção oeste do estado, região de Dom Pedrito, onde os sucessivos pulsos foram responsáveis pela construção de platôs. $O$ presente trabalho caracteriza parte desta região, a porção sul do Platô do Taquarembo, discutindo a origem, características geoquímicas e evolução deste vulcanismo ácido.

A SEQUÊNCIA VULCÂNICA ÁCIDA DO PLATÔ DO TAQUAREMBÓ O vulcanismo ácido desta região, segundo últi mas revisões, pode ser referido como Aloformação Acampamento Velho (Paim et al. 1995). As unidades basais da Sequência Vulcânica Ácida (SVA) fazem contato através de discordância angular e falhamentos, com as rochas granulíticas do Complexo Granulítico Santa Maria Chico (Nardi \& Hartmann 1979) e sedimentitos da Formação Maricá (Ribeiro \& Fantinel 1978), sobrepondo-se concordantemente aos andesitos da Formação Hilário (Ribeiro \& Fantinel 1978) . As unidades superiores mostram-se encobertas parcialmente por rochas areno-pelíticas da sequência gondwânica. Ocorre também associado a estes vulcanitos, granitóides epizonais do Complexo Anelar Leões (Gastai et al. 1992)(Fig. 1)

A SVA é constituída por uma sucessão de rochas efusivas (lavas traquidacíticas à riolíticas), depósitos piroclásticos (queda e fluxo) e vulcanoclásticas, cuja sequência de eventos refletem as variações da atividade vulcânica no Platô do Taquarembo (Sommer 1994). As rochas da SVA são organizadas em diferentes fácies, que de acordo com a sucessão de eventos, podem estar vinculadas aos seguintes episódios:

i) evento formador de derrames de composição traquidacítica à riolítica (associação de rochas efusivas I), antecedido por uma fase piroclástica, formadora de depósitos piroclásticos de queda; ii) evento predominantemente explosivo, formador de brechas vulcanoclásticas, depósitos de fluxo piroclástico, posteriormente ressedimentados e ignimbritos. Este evento é sucedido de novas emissões de lavas, responsável pela formação da associação de rochas efusivas II que apresentam características semelhantes às lavas da associação I.

Os depósitos piroclásticos de queda representam as unidades basais da SVA, ocorrendo sobre as rochas andesíticas da Formação Hilário e marcando o contato com as rochas sieníticas do Complexo Anelar Leões. Os depósitos são representados por rochas tufáceas que ocorrem na forma de finos pacotes tabulares, decimétricos, acamadados, com estruturas tipofining-up e laminação plano paralela. Petrograficamente podem ser classificadas como tufos e lápilli-tufos a cristal e líticos.

A associação de rochas efusivas I ocorre sobreposta aos depósitos piroclásticos basais da SVA, bem como às rochas granulíticas e andesíticas do embasamento. São representadas por lavas, cuja composição no TAS (Lê Bas et al. 1986) varia de traquidacítica à riolítica. No campo observa-se disjunções colunares, foliações e vesículas preenchidas por carbonato e/ou quartzo. As rochas apresentam textura porfirítica, com percentagem de fenocristais inferior a $10 \%$, sendo estes subédricos de feldspato alcalino e subordinadamente quartzo, envoltos por matriz originalmente hemicristalina, quartzo-feldspática. Apatita, magnetita e zircã̃o microcristalino são as fases acessórias,

A fácies de brechas vulcanoclásticas ocorre próximo ao contato da SVA com o Complexo Anelar Leões, sobrepondo-se as rochas efusivas da associação I. São constituídas por litoclastos tamanho bloco (fragmentos de rochas andesíticas, traquidacíticas, riolíticas e granitóides), envoltos por matriz com fragmentos tamanho lápilli.

Os depósitos de fluxo piroclástico ocorrem sobrepondo-se aos depósitos de brechas e as rochas efusivas da associação I. São constituídos principalmente por depósitos de blocos de fluxo de blocos e bombas e subordinadamente ignimbritos, dispostos em um sucessão de camadas sub-horizontais. Observa-se internamente nas camadas, uma gradação normal de litoclastos e inversa de púmice. Mostram-se mal selecionados, sendo constituídos por piroclastos tamanho lápilli, 

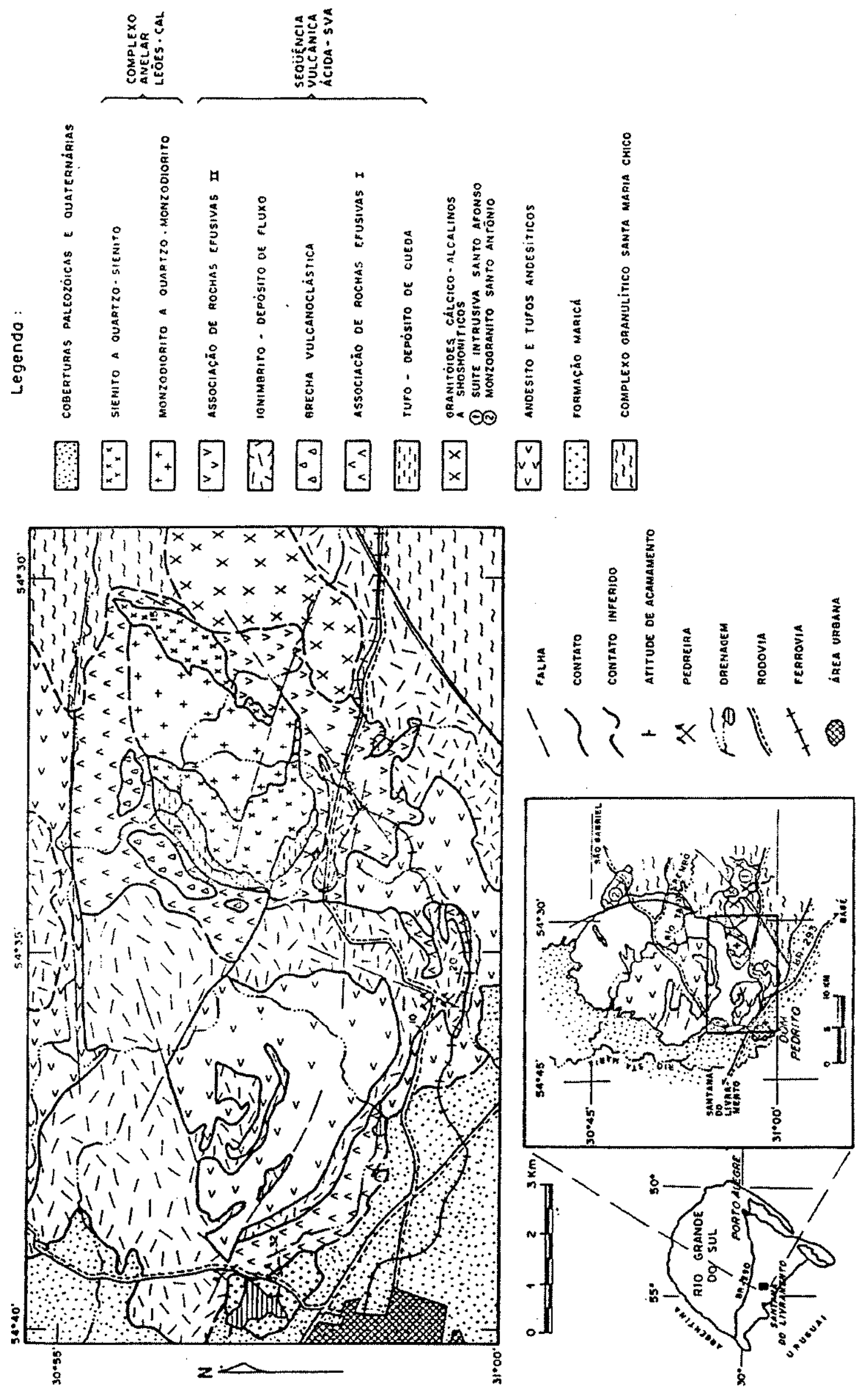
subordinados por cinzas e fragmentos de blocos e bombas e púmice. Os fragmentos de púmice mostram-se desvitrificados, gerando intercrescimentos microcristalinos de quartzo e feldspato alcalino, evidenciando as texturas axiolítica e esferulítica. A disposição geométrica das camadas bem como a sua organização interna das mesmas, permitem inferir um episódio de ressedimentação para estes depósitos. Associados a esta fácies, ocorrem camadas centimétricas à decimétricas de tufos a pó, com estruturas de ondulação que podem ser inferidos como depósito de surgência piroclástica.

Os ignimbritos sobrepõem os depósitos de fluxo ressedimentados, ocorrendo como pacotes não estratificados e mal selecionados, com soldamento bastante acentuado. São caracterizados por fiammes, textura eutaxítica, textura axiolítica, púmice, litoclastos e cristaloclastos. Os fragmentos apresentam tamanho predominantemente lápilli.

A associação de rochas efusivas II representa a última unidade da SVA, sendo constituída por lavas riolíticas e traquidacíticas que sobrepõem-se em áreas restritas, aos depósitos de fluxo piroclástico. Apresentam características texturais e composicionais semelhantes às lavas da associação I. Além da mineralogia descrita anteriormente, foram observados na associação II, restos de microfenocristais parcialmente oxidados de anfibólio alcalino, opticamente identificados como arfvedsonita/riebeckita.

As características estratigráficas, como a deposição sobre o embasamento granulítico ou sobre as rochas traquiandesíticas da Formação Hilário, aliadas a presença de disjunções colunares nos derrames e ausência de hialoclastos entre os piroclastos, sugerem um vulcanismo continental em um ambiente dominantemente subaéreo.

\section{LITOQUÍMICA DAS ROCHAS VULCÂNICAS ÁCIDAS}

Para o estudo geoquímico da SVA do Platô do Taquarembó foram selecionadas 30 amostras para análise de elementos maiores e traços $(\mathrm{Rb}, \mathrm{Sr}, \mathrm{Ba}$ e $\mathrm{Zr}$ ). Destas, 13 foram analisadas para $\mathrm{Nb}, \mathrm{Y}$ e $\mathrm{Ga}$ e 5 para elementos terras raras (ETR).

Os elementos maiores e traços foram analisados no Laboratório de Geoquímica do Instituto de Geociências da UFRGS. Na determinação de $\mathrm{SiO}_{2}, \mathrm{Al}_{2} \mathrm{O}_{3}, \mathrm{TiO}_{2}, \mathrm{CaO}, \mathrm{P}_{2} \mathrm{O}_{5}, \mathrm{~K}_{2} \mathrm{O}, \mathrm{Fe}_{2} \mathrm{O}_{3}, \mathrm{Zr}, \mathrm{Rb}, \mathrm{Sr}$ e $\mathrm{Ba}$ foi utilizado o método da espectrometria de fluorescência de raios-X, em aparelho de marca Rigaku, utilizando-se tubo de cromo. O método de espectrometria de absorção atómica foi utilizado na determinação de $\mathrm{FeO}_{\mathrm{T}}, \mathrm{MnO}$ e $\mathrm{MgO}$. O FeO foi obtido por titulação, segundo o método de Wilson e o $\mathrm{Na}_{2} \mathrm{O}$ por fotometria de chama. Os valores de perda ao fogo $\mathrm{e}_{2} \mathrm{O}$ " foram determinados, respectivamente, em forno a $1000^{\circ} \mathrm{C}$ e em estufa a $\pm 105^{\circ} \mathrm{C}$. As análises de $\mathrm{Nb}, \mathrm{Y}, \mathrm{Ga}$ e terras raras foram realizadas através de espectrometria de plasma (ICP). Estas análises foram feitas na divisão laboratorial da GEOSOL (Geologia e Sondagens Ltda.) - GEOLAB - sob a responsabilidade do Dr. Cláudio Vieira Dutra.

Foram analisadas amostras de lavas das associações de rochas efusivas I e II e ignimbritos, vinculados aos depósitos de fluxo piroclástico. Evitou-se as amostras onde os processos de alteração poderiam remover elementos como sódio e potássio, modificando desta maneira, a composição magmática original. Desta forma, utilizou-se amostras que não apresentaram na petrografia, vesículas, fenómenos de silicificação ou com matriz argilosa. Foram evitadas ainda, amostras que possuíam um grande conteúdo de litoclastos. Os dados químicos discutidos neste item são apresentados na Tabela 1 .

As rochas da SVA foram classificadas a partir do diagrama de classificação química de rochas vulcânicas (TAS - Lê Bas et al. 1986), como riólitos, traquidacitos ( Qzn $>20 \%$ ) e traquitos ( Qzn $<20 \%$ ), sendo os primeiros os termos composicionais dominantes.

As rochas da SVA apresentam teores de $\mathrm{SiO}_{2}$ variando entre 64,9 a $79,6 \%$, sendo o intervalo $64,9-73 \% \mathrm{SiO}_{2}$ comum nas lavas desta sequência, enquanto que os teores mais altos (> 74\%) são encontrados entre os ignimbritos. O comportamento químico destas últimas assemelha-se aos riólitos denominados alta sílica (Mahood \& Hildreth 1983, Metz \& Mahood 1991). Os elementos maiores, em geral, possuem uma correlação negativa com a $\mathrm{SiO}_{2}$ (Fig. 2) e esta tendência sugere, especialmente para os conteúdos mais baixos deste óxido, mecanismos de fracionamento de minerais, provavelmente feldspato alcalino, plagioclásio, magnetita e clinopiroxênio.

No diagrama de Shand (Maniar \& Piccoli 1989) constata-se dois comportamentos diferentes entre as rochas da SVA (Fig. 3). As lavas ocupam o campo metaluminoso a peralcalino, enquanto que os ignimbritos mostram uma natureza peraluminosa que pode ser explicada pela perda de $\mathrm{Na}^{+}$e $\mathrm{K}^{+}$por processos de alteração.

A afinidade comendiítica dos riólitos e traquitos da SVA é evidenciada através da utilização dos diagramas $\mathrm{SiO}_{2} \times \mathrm{Zr} / \mathrm{TiO}_{2}$ (Winchester \& Floyd 1977) (Fig. 4) e $\mathrm{FeO}_{\mathrm{t}} \times \mathrm{Al}_{2} \mathrm{O}_{3}$ ( MacDonald 1974) (Fig. 5).
Algumas lavas menos diferenciadas e estratigraficamente mais precoces ocupam o campo dos pantelleritos. No entanto, a maioria das rochas da SVA possui um caráter comendiítico, cujo trend é similar ao de outras associações riolíticas com esta afinidade, como pode ser observado através do diagrama $\mathrm{Al}_{2} \mathrm{O}_{3}$ x Qz normativo (Fig. 6) (c.f. MacDonald 1974).

A SVA pode ser classificada como uma sequência tipicamente alcalina com trend metaluminoso a peralcalino. Os altos valores do índice agpaítico $(>0,85)$ e a elevada razão $\mathrm{FeOt} / \mathrm{FeOt}+\mathrm{MgO}$ (Tabela 1) são compatíveis com os de outras associações magmáticas alcalinas (Éwart 1979) e superpõem-se aos dados obtidos para os granitóides de afinidade alcalina da Suíte Intrusiva Saibro - RS, temporalmente correlacionáveis com a Fm. Acampamento Velho, conforme descrito por Nardi (1991), Gastai \& Nardi (1992) e Gastai et al (1992).

A SVA apresenta, caracteristicamente, altas concentrações de HSFE, especialmente $\mathrm{Zr}$, Y, Ga e Nb. Além destes elementos observa-se também, um enriquecimento em $\mathrm{Rb}$ e um empobrecimento relativo em $\mathrm{Ba}$ e Sr. Os dados são apresentados na Tabela 1 e os diagramas de variação podem ser observados nas figuras 7 e 8 . O Zr apresenta valores elevados, com teores de 500 a 1200 ppm, mostrando uma leve correlação positiva com a sílica. Dados experimentais indicam que os altos teores de $\mathrm{Zr}$ em magmas ácidos peralcalinos devem-se a maior solubilidade de $\mathrm{Zr}^{+4}$ em líquidos com altas proporções em álcalis em relação a Si${ }^{4+}$ e $\mathrm{Al}^{3+}$, cátions formadores de polímeros (Watson 1979, Watson \& Harrison 1983), determinando a cristalizacão tardia de zircão, o que em geral ocorre de forma microcristalina (White 1992) Esta hipótese é coerente com os estudos petrográficos das rochas da SVA, onde o zircão ocorre como acessório e microcristalino. Os teores de $\mathrm{Nb}, \mathrm{Y}$ e Ga possuem tendência de enriquecimento com a diferenciação e a dispersão observada em alguns diagramas pode estar relacionada à complexação com flúor e cloro (Turner et al 1992, Westrich et al 1988) (Fig. 8).

Os altos teores para $\mathrm{Zr}, \mathrm{Nb}, \mathrm{Y}$ e $\mathrm{Ga}$ e o enriquecimento em $\mathrm{Rb}$, juntamente com os baixos teores de $\mathrm{Ba}$ e $\mathrm{Sr}$, são característicos de magmatismo ácido de afinidade alcalina (Pearce et al 1984, Whalen et al 1987, Nardi 1991).

No diagrama $\mathrm{Rb} \times(\mathrm{Y}+\mathrm{Nb})$ de Pearce et al (1984) (Fig. 9), as amostras da SVA ocupam o campo de granitos intraplaca e pósorogênicos, tendência também comum em outras associações magmáticas tipicamente pós-orogênicas, como Snowdon Rhyolites (Leat et al 1986) e Suíte Intrusiva Saibro (Nardi \& Bonin 1991, Gastai et al 1992). As razões $\mathrm{Zr} / \mathrm{Nb}$ constantes com valores superiores a 10 , são também sugestivos de um ambiente pós-orogênico, com o magmatismo ainda revelando os efeitos da subducção. Esta hipótese é também coerente com o diagrama $\mathrm{Zr} \times \mathrm{Nb}$ (Leat et al 1986 ), para distinguir suítes riolíticas e traquíticas, tipicamente de ambiente intraplaca, das suítes vulcânicas pós-orogênicas (Fig. 10). O campo ocupado pelas amostras da SVA coincide com o posicionamento de Snowdon Rhyolites que são pós-orogênicos. O suave aumento na razão $\mathrm{Zr} / \mathrm{Nb}$ da SVA, quando comparado com as amostras da Suíte Intrusiva Saibro, intrusivos alcalinos nesta região, pode ser explicada pela perda de $\mathrm{Nb}$ em complexos de $\mathrm{F} \mathrm{e} \mathrm{Cl}$, durante a degaseificação (Turner et al 1992, Westrich et al 1988). Os valores de Zr superiores a $500 \mathrm{ppm}$, segundo Leat et al (1986)., indicam o caráter peralcalino da SVA.

O conteúdo de ETR da SVA (Tabela 2$)$ é elevado $\left(\Sigma_{\mathrm{ETR}}=2575-\right.$ 1538) e os padrões normalizados indicam um fracionamento em ETR pesados com razões $C_{\mathrm{eN}} / Y_{\mathrm{bN}}$ variando entre 8,71 e 25,24 (Fig. 11) e um forte enriquecimento em ETR leves $\left(\Sigma_{\mathrm{ETR}}=2277-1245\right)$, além de um baixo fracionamento nestes elementos como observado através das razões $\mathrm{L}_{a \mathrm{~N}} / \mathrm{S}_{\mathrm{mN}}=3,83-6,11$. Os padrões de ETR da SVA indicam uma anomalia negativa de $\mathrm{Eu}\left(\mathrm{Eu} / \mathrm{Eu}^{*}=0,15-0,26\right)$, que está provavelmente relacionado a um fracionamento de feldspatos. Observa-se também, um leve aumento no fracionamento em ETR leves com o aumento da diferenciação (Fig. 11).

O comportamento de alguns elementos tracos e ETR da SVA. quando normalizados segundo os padrões do ORG (Pearce et al 1984), é apresentado no diagrama multi-elementar da figura 12. Observa-se um enriquecimento generalizado em elementos mais incompatíveis, como evidenciado pela variação entre os valores normalizados do $\mathrm{Yb}$ para o $\mathrm{K}_{2} \mathrm{O}$. Outras feições características são a anomalia negativa em Ba, o leve enriquecimento em Ce em relação aos elementos adjacentes e um maior enriquecimento de $\mathrm{K}_{2} \mathrm{O}$ e $\mathrm{Rb}$ em relação ao $\mathrm{Nb}$. Estas características são comuns em associações derivadas de uma fonte mantélica enriquecida em elementos incompatíveis, mas que tiveram alguma forma de participação crustal.

O padrão médio das análises química das rochas da SVA, quando comparado com os padrões de associações tipicamente alcalinas 
Tabela $\mathrm{l}$ - Resultados de análise química de elementos maiores (\% em peso) e traços (ppm) da SVA. Obs.: $\mathrm{Fe} \#=\mathrm{FeO} / \mathrm{FeO}+\mathrm{MgO} ; \mathrm{IAG}=$ indice agpaítico $\left(\mathrm{Na}_{2} \mathrm{O}+\mathrm{K}_{2} \mathrm{O} / \mathrm{Al}_{2} \mathrm{O}_{3}\right)$ molar.

\begin{tabular}{|c|c|c|c|c|c|c|c|c|c|c|c|c|c|c|c|}
\hline \multicolumn{10}{|c|}{ ASSOCIAÇÃO DE ROCHAS EFUSIVAS I } & \multicolumn{6}{|c|}{ ASSOCIAÇĀO DE ROCHAS EFUSIVAS II } \\
\hline & CC-45B & $\operatorname{CC45A}$ & $\operatorname{cc}-133$ & Cc-19 & $\operatorname{ccs}-6$ & $\operatorname{cc}-65$ & $\mathrm{cc-65}$ & CC.41' & $\mathrm{CC}-41$ & CC-194 & $\operatorname{ccs} 06 \mathrm{~A}$ & CC-121 & $\operatorname{cc} .79$ & CC-109 & $\operatorname{ccs} 106$ \\
\hline $\mathrm{SiO}_{2}$ & 66,50 & 66,30 & 68,34 & 70,84 & 71,18 & 71,56 & 71,76 & 79,60 & 79,65 & 65,08 & 67,44 & 69,24 & 73,32 & 74,88 & 74,93 \\
\hline $\mathrm{TiO}_{2}$ & 0,58 & 0,55 & 0,48 & 0,29 & 0,28 & 0,28 & 0,28 & 0,18 & 64,91 & 0,53 & 0,53 & 0,39 & 0,28 & 0,02 & 0,27 \\
\hline $\mathrm{Al}_{2} \mathrm{O}_{3}$ & 11,95 & 12,01 & 13,25 & 12,28 & 12,13 & 12.13 & 12,24 & 10,02 & 10.13 & 13,79 & 13,39 & 13,50 & 11.49 & 10,43 & 10,87 \\
\hline $\mathrm{Fe}_{2} \mathrm{O}_{3}$ & 4,80 & 5.52 & 2,93 & 1,57 & 0,84 & 1,77 & 1,28 & 0,38 & 0,49 & 2,56 & 1,55 & 4,21 & 2,61 & $3,6 \mathrm{~J}$ & 2,42 \\
\hline Mno & 0,20 & 0,18 & 0,26 & 0,13 & 0,16 & 0,13 & 0,13 & 0,01 & 0,01 & 0,21 & 0,21 & 0,03 & 0,04 & 0,01 & 0,06 \\
\hline $\mathrm{MgO}$ & 0,48 & 0,38 & 0,43 & 0,57 & 0,18 & 0,94 & 0,63 & 0,02 & 0,02 & 0,35 & 0,61 & 0,41 & 0,05 & n.d. & 0,05 \\
\hline $\mathrm{CaO}$ & 1,55 & 1,13 & 0,60 & 0,41 & 0,60 & 0,39 & 0,40 & 0.17 & 0.14 & 2,70 & 1,10 & 0,32 & 0,11 & 0,12 & 1,10 \\
\hline $\mathrm{Na}_{2} \mathrm{O}$ & 4,31 & 4,18 & 4,31 & 4,58 & 4,28 & 4,45 & 4,45 & 3,77 & 3,71 & 4,25 & 5,32 & 4,25 & 4,18 & 4,18 & 4,25 \\
\hline$K_{2} \mathrm{O}$ & 4,66 & 4,72 & 4,61 & 5,13 & 4,89 & 5,09 & 5,21 & 3,89 & 3,85 & 4,38 & 4,95 & 4,57 & 3,45 & 4,74 & 1,45 \\
\hline $\mathrm{H}_{3} \mathrm{O}$ & 0,19 & 0,19 & 0,67 & 0,20 & 0,32 & 0,10 & 0,17 & 0,24 & 0,22 & 0,38 & 0,21 & 0,50 & 0,38 & 0,23 & 0.25 \\
\hline $\mathbf{P}, \mathbf{F}$ & 2,79 & 2,26 & 1,28 & 1,63 & 1,59 & 1,67 & 1,66 & 1,03 & 1,05 & 2,73 & 0,88 & 1,12 & 1,27 & 0,26 & 1,62 \\
\hline Fotal & 99,23 & 99,83 & 99,51 & 100,0 & 99,26 & 100,6 & 100.55 & 100,61 & 100.70 & 99,40 & 99,12 & 99,27 & 99.17 & 99,34 & 99.17 \\
\hline $\mathbf{R b}$ & 67 & 82 & 65 & 109 & 103 & 120 & 121 & $10 !$ & 106 & 58 & 78 & 99 & 80 & 143 & 22 \\
\hline Ba & 144 & 174 & 143 & 57 & 43 & 47 & 49 & 129 & 140 & 367 & 44 & 1931 & 386 & 33 & 147 \\
\hline Sr & 30 & 30 & 47 & 30 & n.d. & 30 & 30) & n.d. & n.d. & 231 & 30 & 181 & 46 & n.d. & 248 \\
\hline $\mathbf{Z r}$ & 573 & 597 & 620 & 858 & 873 & 940 & 947 & 1117 & 1168 & 426 & $78]$ & 379 & 967 & 876 & 1014 \\
\hline Nb & 26 & 26 & n.a. & 39 & 40. & n.a. & n.a. & ต.... & n.a. & п.a. & 39 & n.a. & n.a. & tha. & ก. 1. \\
\hline Ga & 23 & 27 & n.t. & 19 & 23 & n.a. & n.a. & n.a. & n.a. & n.a. & 26 & n.a. & n.a. & п..а. & n.a. \\
\hline $\mathbf{Y}$ & 93 & 93 & n.a. & 130 & 130 & ต.a. & n.a. & n.a. & n.a. & n.a. & 95 & n.a. & n.a. & п. & n.a. \\
\hline IAGP & 1,02 & 0,98 & 0,91 & 1,07 & 1,02 & 1,06 & 1,06 & 1,04 & 1,01 & 0,85 & 1,06 & 0,88 & 0,92 & 1,15 & 0,79 \\
\hline Fe\# & 0,94 & 0,95 & 0.92 & 0.87 & 0,95 & 0,86 & 0,85 & 0,99 & 0,98 & 0,92 & 0,88 & 0,92 & 0,99 & n.d. & 0,99 \\
\hline \multicolumn{16}{|c|}{ DEPÓSITOS DE FLUXO PIROCLÁSTICO } \\
\hline & CC.74 & $\mathrm{CC}-188$ & CCMBSC & $\mathrm{CC}-34$ & $\operatorname{cc}-42$ & $\operatorname{cc} \cdot 34 \mathrm{C}$ & $\operatorname{cc}-234$ & $\operatorname{cc}-25$ & $\mathrm{CC}-177$ & Cc-112 & CC.URA & cc.59A & CC-93A & CC-12A & \\
\hline $\mathrm{SiO}_{2}$ & 72,55 & 72.61 & 72,67 & 72,98 & 74,09 & 74,58 & 74,79 & 75,42 & 75.74 & 76,15 & 76,25 & 76,29 & 76,89 & 77,59 & \\
\hline $\mathrm{TiO}_{2}$ & 0,20 & 0,41 & 0,40 & 0,43 & 0,30 & 0,28 & 0,30 & 0,31 & 0,28 & 0,20 & 0,23 & 0,26 & 0,24 & 0,22 & \\
\hline $\mathrm{Al}_{2} \mathrm{O}_{3}$ & 12,84 & 12,72 & 12,12 & 12,16 & 11,31 & 11,36 & 11,45 & 11,01 & 10,83 & 11.22 & 10,88 & 10,10 & 10,98 & 10,31 & \\
\hline $\mathrm{Fe}_{2} \mathrm{O}_{3}$ & 1,59 & 3,35 & 2,89 & 3,59 & 2,50 & 3,28 & 3,00 & 3,43 & 3.50 & 2,88 & 2,84 & 2,60 & 1,97 & 2,25 & \\
\hline $\mathrm{FeO}$ & 1,75 & 0,90 & 1.20 & 0,94 & 1,22 & 0,95 & 1,15 & 0,51 & 0,98 & 0,78 & 1,17 & 0.98 & 1,24 & 1,33 & \\
\hline Mno & 0,07 & 0,04 & 0,03 & 0,03 & 0,03 & 0,09 & 0,08 & 0,10 & 0,02 & 0,01 & 0,02 & 0.02 & 0,02 & 0,01 & \\
\hline MgO & 0,07 & 0,10 & 0.57 & 0,02 & 0,44 & 0,54 & 0,01 & 0,10 & n.d. & n.d. & 0,49 & 0.16 & 0,09 & 0,46 & \\
\hline $\mathrm{CaO}$ & 0,51 & 0,27 & 0.34 & 0,27 & 0,11 & 0.11 & 0,16 & 0,15 & 0.12 & 0,10 & 0,09 & 0.18 & 0,15 & 0,13 & \\
\hline $\mathrm{Na}_{2} \mathrm{O}$ & 4,31 & 4,31 & 3,20 & 4,48 & 4,72 & 4,67 & 4,31 & 3,71 & 4,18 & 4,01 & 3,63 & 3,57 & 4,21 & 3,47 & \\
\hline $\mathrm{K}_{2} \mathrm{O}$ & 4,19 & 3,90 & 5,30 & 3,92 & 4,26 & 4,00 & 3,58 & 4,17 & 3,46 & 4,06 & 4,25 & 2.66 & 3,27 & 3,96 & \\
\hline $\mathrm{P}_{2} \mathrm{O}_{3}$ & 0.01 & n.d. & 0,02 & 0,03 & 0,10 & n.d. & ת.d. & 0,01 & $\mathrm{n}, \mathrm{d}$ & n.d. & 0,02 & 0,01 & n.d. & 0,01 & \\
\hline $\mathrm{H}_{3} \mathrm{O}^{\circ}$ & 0,30 & 0,21 & 0,23 & 0,12 & 0.11 & 0.11 & 0,11 & 0,22 & 0,21 & 0,34 & 0,22 & 0,42 & 0,18 & 0,17 & \\
\hline $\mathbf{P}, \mathbf{E}$ & 1,14 & 0,40 & 1,07 & 0,52 & 0,10 & 0,19 & 0,14 & 0,87 & 0,20 & 0,86 & 0,75 & 2,04 & 0,46 & 0,37 & \\
\hline Total & 99,53 & 99,22 & 100,04 & 99,49 & 99,29 & 300.16 & 99,08 & 100.01 & 99,52 & 100,61 & 100,24 & 99.29 & 99,70 & 100,62 & \\
\hline Rb & 124 & 86 & 135 & 99 & 160 & 103 & 114 & 136 & 105 & to8 & 118 & 73 & 120 & 146 & \\
\hline $\mathbf{E a}$ & 477 & 548 & 450 & 355 & 73 & 119 & 75 & 122 & 41 & 135 & 119 & 433 & 41 & 157 & \\
\hline Sr & 48 & 23 & 55 & 32 & 30 & 37 & 30 & 30) & 14 & 5 & 34 & 105 & 30 & 40 & \\
\hline $\mathbf{Z r}$ & 360 & 544 & 595 & 656 & 719 & 562 & 570 & 684 & 803 & 733 & 801 & 496 & 737 & 781 & \\
\hline $\mathrm{Nb}$ & 42 & n.a. & 36 & 35 & 24 & 32 & 32 & 36 & n.a. & n.a. & n.a. & n.a. & 34 & n...a. & \\
\hline Ga & 26 & n.a. & 34 & 30 & 27 & 30 & 29 & 28 & n.a. & n.a. & n.a. & n.a. & 33 & n.a. & \\
\hline $\mathrm{Y}$ & 130 & n.a. & 140 & 120 & 120 & 130 & 110 & 140 & n.a. & ก.а. & n.a. & n.a. & 140 & n.a. & \\
\hline IAGP & 0,90 & 0,89 & 0,91 & 0,95 & 1,09 & $1,(1 \%$ & 0,96 & 0,96 & 0,98 & 0,98 & 0,88 & 0,86 & 0,95 & 0,97 & \\
\hline Fe\# & 0,98 & 0,97 & 0,87 & 0,99 & 0,89 & 0,88 & 0,99 & 0,97 & rt.d. & n.d. & 0,88 & 0,95 & 0,97 & 0,88 & \\
\hline
\end{tabular}



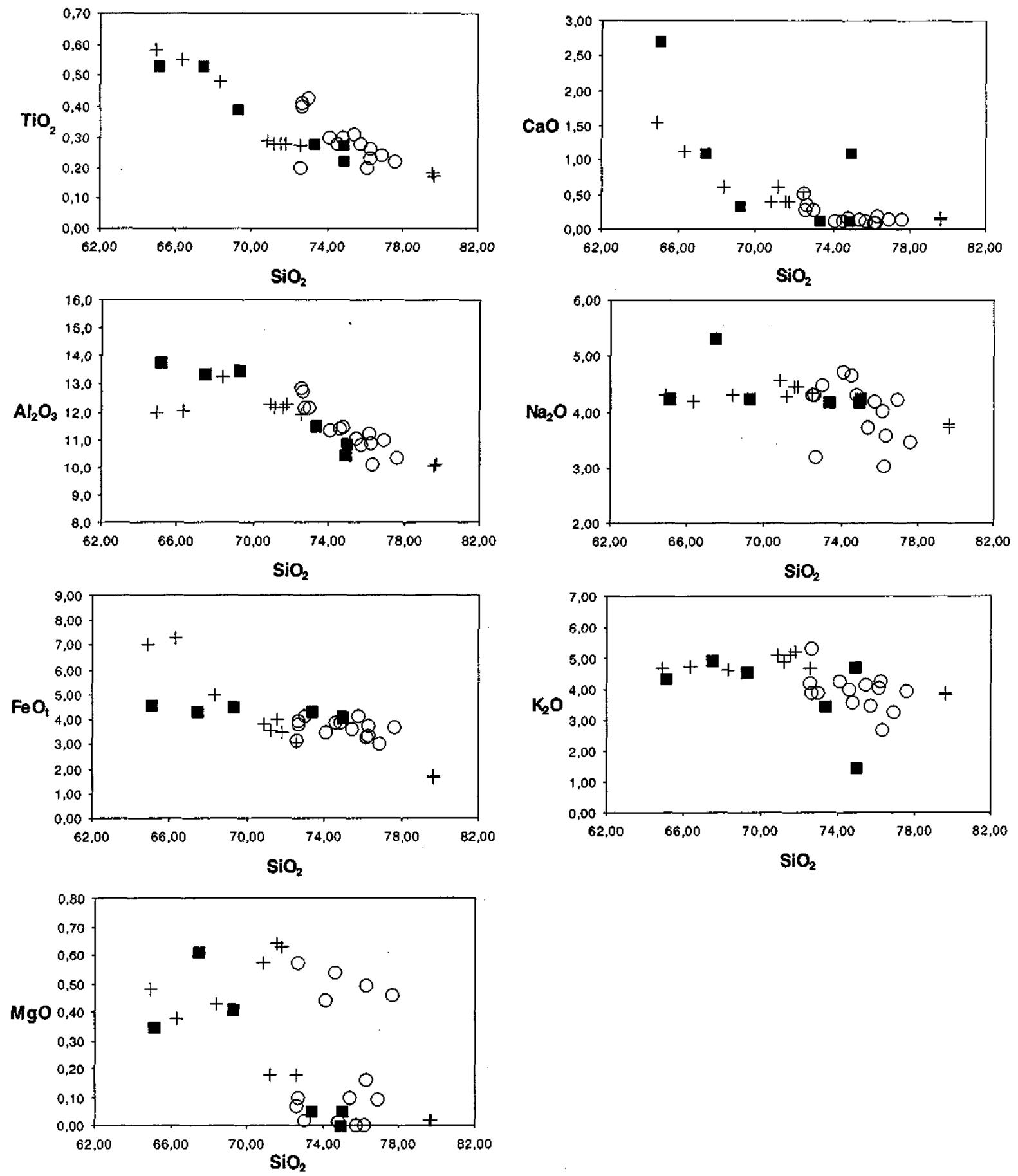

Figura 2 - Amostras da SVA plotadas em diagramas de Harker. Legenda: + = associação de rochas efusivas I; $O$ = depósitos defluxo piroclástico;

- associação de rochas efusivas $H$.

anorogênicas (e. g. Panteleria, Villari 1974; Naivasha Rhyolite, Kenya Rift - MacDonald et al. 1987), posiciona-se de forma intermediária entre os valores constatados em sequências anorogênicas intraplacas de ilhas oceânicas e de rifts continentais, destacando-se para a SVA uma anomalia de Ba menos acentuada e valores mais baixos de $\mathrm{Nb}$ (Fig. 13). A comparação com sequências vulcânicas cálcio-alcalinas (Bishop Tuff, Hildreth 1981) e alcalinas pós-orogênicas (Snowdow, Leat et al. 1986), indica um maior enriquecimento em LILEs da SVA em relação as primeiras e uma notável semelhança com os tipos pós-orogênicos (Fig. 14).

Os altos valores de ETR encontrados na SVA, principalmente de ETR leves, indicam, juntamente com altos valores encontrados para $\mathrm{Zr}, \mathrm{Nb}, \mathrm{Y}$ e baixos para $\mathrm{Ba}$ e $\mathrm{Sr}$ a natureza alcalina de seu magmatismo. $\mathrm{O}$ diagrama de ETR exibe um típico padrão de associações magmáticas pós-orogênicas, coerentes com os resultados obtidos em diagramas discriminantes para elemento traço (e.g. $\mathrm{Zr} \times \mathrm{Nb}$ ).

\section{GÊNESE E EVOLUÇÃO GEOQUÍMICA DO MAGMATISMO}

DA SVA Os processos de diferenciação envolvidos em câmaras magmáticas crustais são em geral complexos, envolvendo recargas, convecção, assimilação e cristalização fracionada, sendo este último o processo dominante na maioria dos casos (Wilson 1993). Normalmente, associações traquíticas-riolíticas têm sua origem atribuída a diferenciação de líquidos básicos, combinando mecanismos de cristalização fracionada e assimilação crustal (AFC), conforme destacado por diversos autores (e.g. Turner et al. 1992, Wilson 1989, Baker \& McBirney 1985, Ewart 1979, Chappell \& White 1992). 


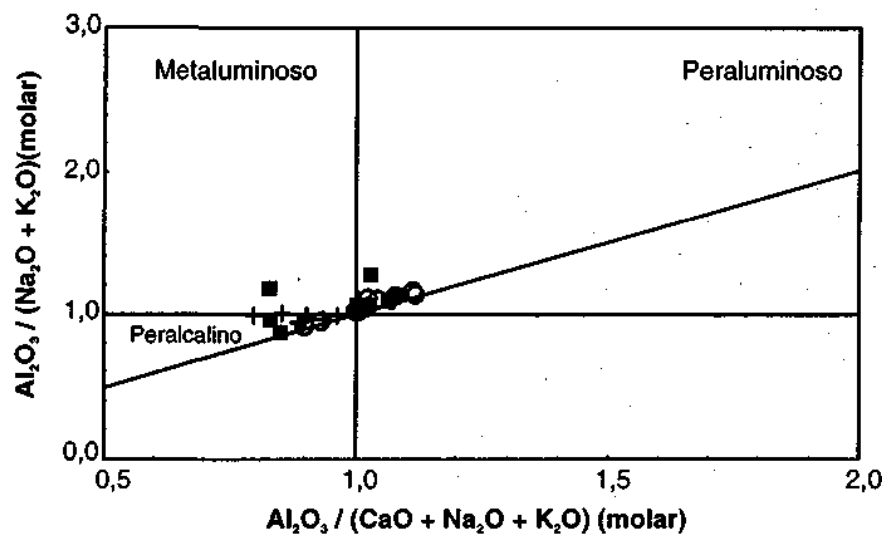

Figura 3 - Amostras da SVA plotadas no diagrama de Shand (Maniar \& Piccoli 1989), demonstrando dois comportamentos diferentes; as lavas ocupam o campo metaluminoso a peralcalino, enquanto que os ignimbritos mostram uma tendência para o campo peraluminoso que pode ser explicada pela perda de $\mathrm{Na}^{+}$e $\mathrm{K}^{+}$por processos de alteração

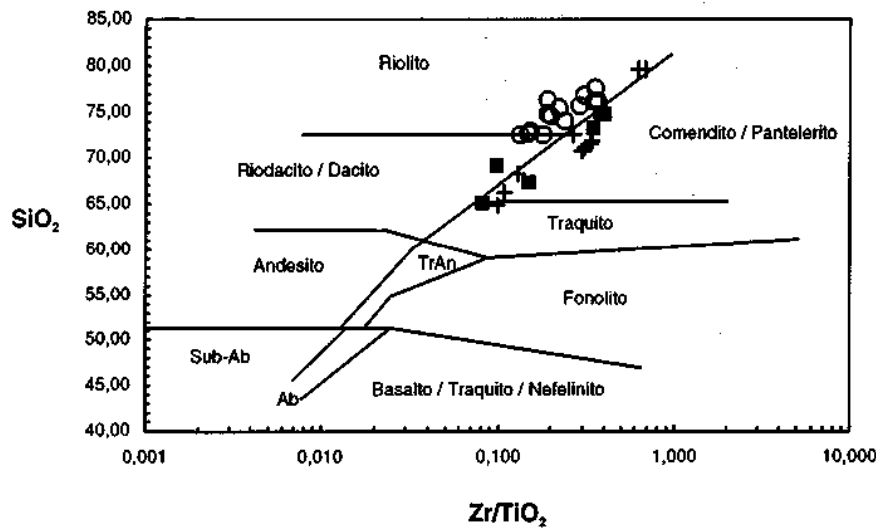

Figura 4 - Amostras da SVA plotadas no diagrama $\mathrm{SiO}_{2} x \mathrm{Zr} / \mathrm{TiO}_{2}$ (Winchester \& Floyd 1977). Legenda: vide figura 2.

Tabela 2 - Conteúdo dos elementos terras raras na SVA. Valores em ppm.

\begin{tabular}{|c|c|c|c|c|c|}
\hline & $\begin{array}{r}\text { ASSO } \\
\text { ROCH }\end{array}$ & $\begin{array}{l}\text { CIAÇÃ } \\
\text { AS EFUS }\end{array}$ & $\begin{array}{l}\text { DE } \\
\text { AAS I }\end{array}$ & $\begin{array}{r}\text { DEPÓSIT } \\
\text { FLU } \\
\text { PIROCLA }\end{array}$ & $\begin{array}{l}\text { S DE } \\
\text { TICO }\end{array}$ \\
\hline & CC-45A & CC-19 & CC-69C & CC-08C & CC-25 \\
\hline La & 292,00 & 150,50 & 185,40 & 124,80 & 118,60 \\
\hline $\mathrm{Ce}$ & 592,70 & 280,20 & 399,70 & 247,00 & 309,50 \\
\hline Nd & 199,60 & 124,10 & 141,50 & 96,80 & 148,50 \\
\hline Sm & 30,08 & 22,54 & 24,27 & 18,70 & 19,48 \\
\hline Eu & 2,20 & 1.11 & 1,22 & 1,28 & 0,88 \\
\hline Gd & 19,05 & 15,31 & 16,74 & 13,40 & 14,68 \\
\hline Dy & 12,19 & 12,12 & 12,85 & 12,67 & 13,82 \\
\hline Ho & 2,42 & 2,45 & 2,63 & 2,63 & 2,85 \\
\hline $\mathbf{E r}$ & 6,48 & 6,71 & 7,42 & 7,58 & 8,12 \\
\hline $\mathbf{Y b}$ & 6,08 & 6,43 & 7,06 & 7,34 & 8,30 \\
\hline $\mathrm{Lu}$ & 0,96 & 0,91 & 1,02 & 1,04 & 1,15 \\
\hline
\end{tabular}

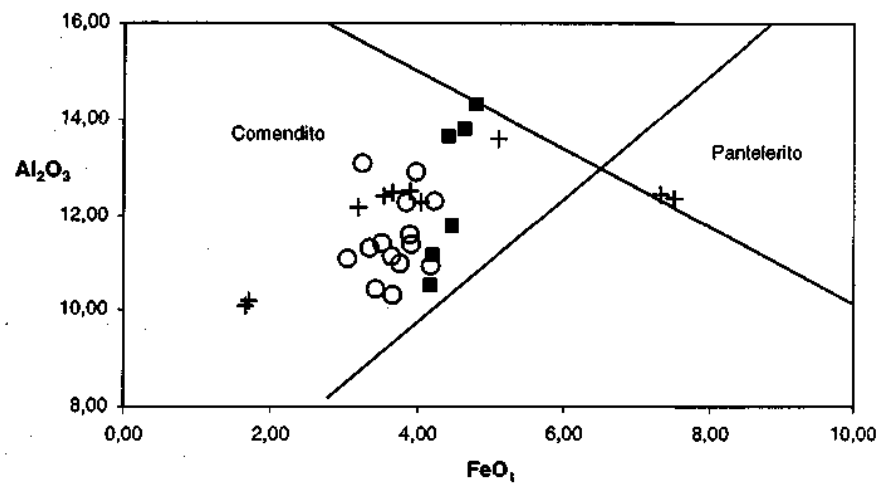

Figura 5 - Amostras da SVA plotadas no diagrama $\mathrm{Al}_{2} \mathrm{O}_{3}$ vs. $\mathrm{FeOt}$ (MacDonald 1974). Legenda: vide figura 2.

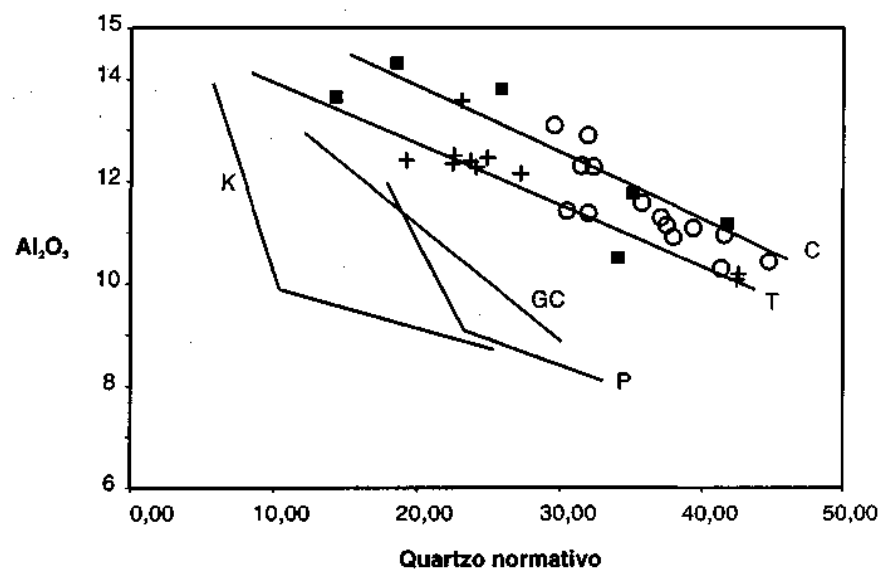

Figura 6 - Diagrama $\mathrm{Al}_{2} \mathrm{O}_{3} \times$ Qwnorm evidenciando a similaridade entre o comportamento das amostras da $\boldsymbol{S V A}$ e um trend comum a rochas comendiíticas (c.f. MacDonald 1974). Legenda: $C=$ "trend" comendiítico generalizado; $T=$ Tugtutor dikes (S. Greenland); $G C=$ Grand Canária; $P=$ Pantelería; $K=$ Central Kenya. Símbolos vide figura 2.

A SVA é constituída por traquitos, traquidacitos e riólitos. Os dados geoquímicos das rochas traquíticas permitem sugerir uma origem para este segmento, a partir de processos de diferenciação de magmas basálticos transicionais ou moderadamente alcalinos (c.f. Wilson 1989). A presença de um magmatismo básico moderadamente alcalino, contemporâneo com o magmatismo ácido é indicada pelos enclaves máficos microgranulares em granitos da Suite Intrusiva Saibro (c.f. Nardi \& Lima 1998). Não descarta-se a possibilidade das rochas básicas alcalinas estarem encobertas pelos vulcanitos da SVA, como constatado no Padthaway Ridge - South Austrália (Turner et al. 1992), onde os termos máfícos foram identificados através de anomalias geofisicas e furos de sondagens.

$\mathrm{Na}$ evolução do magmatismo ácido alcalino do Platô do Taquarembó, testou-se o processo de cristalização fracionada para explicar a origem das rochas riolíticas a partir de líquidos traquíticos. $\mathrm{O}$ programa XLFRAC (Stormer \& Nicholls 1978), foi utilizado no modelamento de elementos maiores para testar a hipótese de cristalização fracionada. Utilizou-se o intervalo de 64 à $74 \%$ de $\mathrm{SiO}_{2}$, como representativo da diferenciação de um líquido traquítico para uma composição riolítica. Neste intervalo, utilizou-se como líquido parental uma composição média entre as rochas traquíticas e traquidacíticas e como líquido final uma média das composições riolíticas até $74 \%$ de $\mathrm{SiO}_{2}$, pertencentes a associação de rochas efusivas I e II. Como apresentado na Tabela 3, os resultados obtidos são bastante satisfatórios e coerentes com os dados petrográficos, podendo-se explicar a origem do líquido riolítico a partir de $21 \%$ de fracionamento de líquido traquítico, gerando um cumulado com $43 \%$ de andesina $\left(\mathrm{An}_{40}\right)$, $34 \%$ feldspato alcalino, $10 \%$ clinopiroxênio (hedembergita e $13 \%$ de magnetita. Em um segundo teste (Tabela 3), utilizou-se um intervalo de $73 \%$ até $79 \%$ de $\mathrm{SiO}_{2}$, para explicar a evolução entre as rochas 

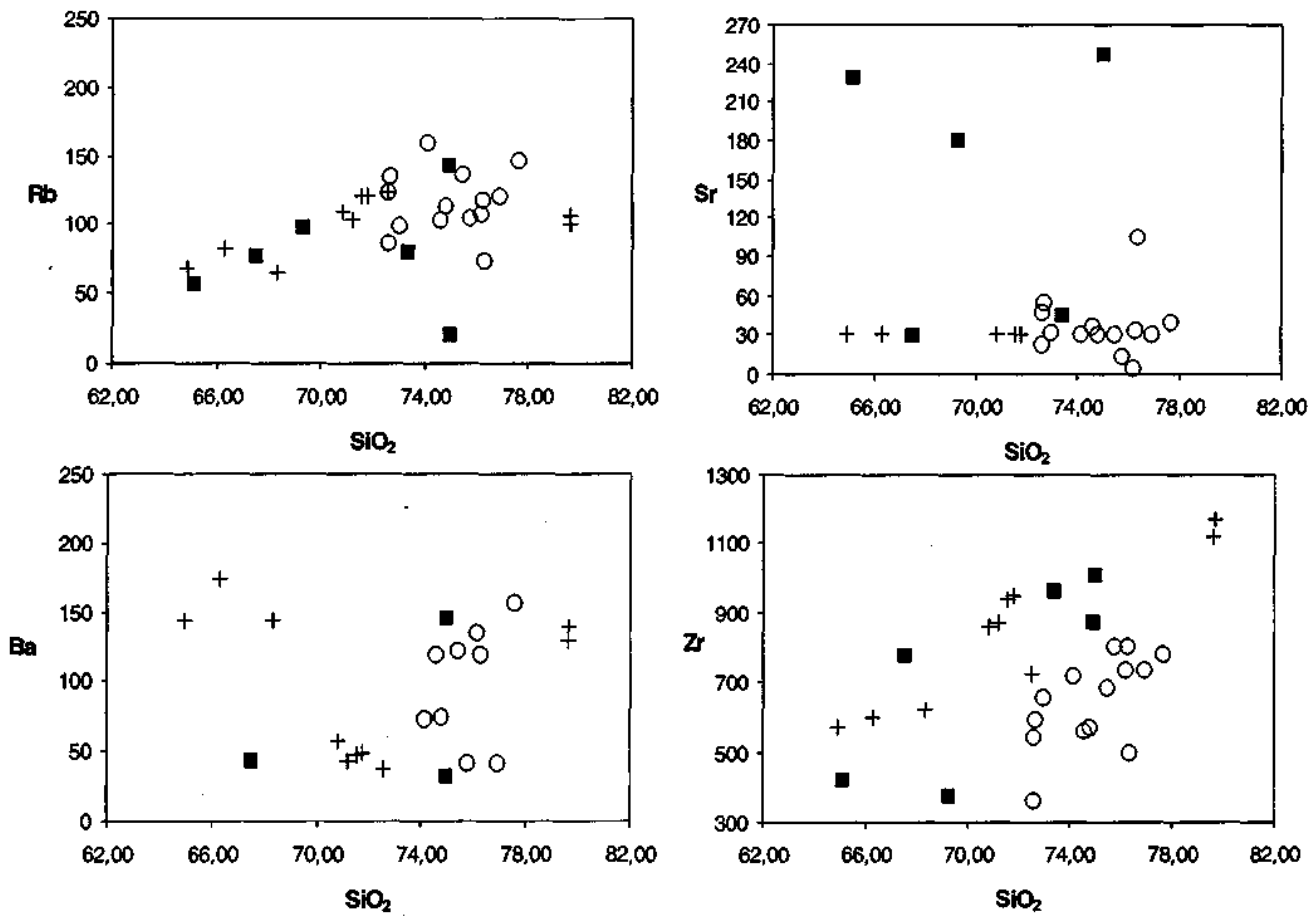

Figura 7 - Diagramas de variação de $R b, B a$, Sr e Zr em relação ao conteúdo de sílica. Símbolos: vide figura 2.
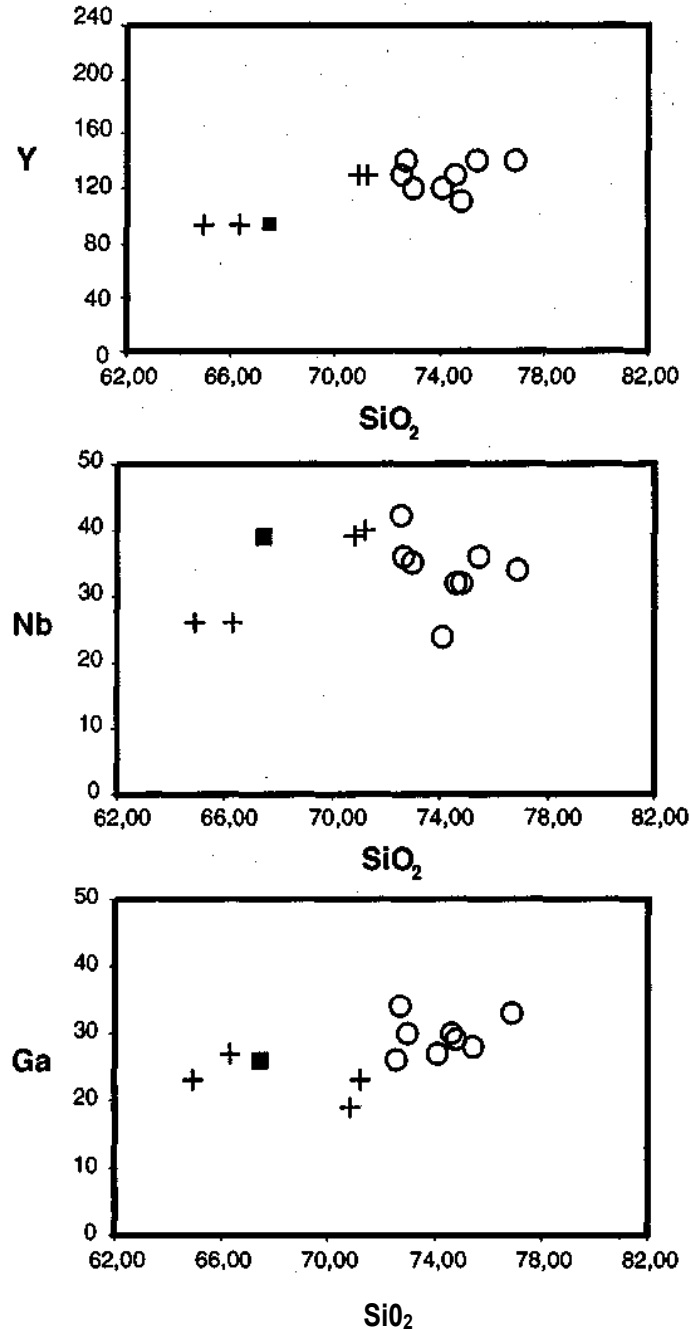

Figura 8 - Diagramas de variação de $\mathrm{Nb}, Y$ e Ga em relação ao conteúdo conteúdo de sílica. Símbolos: vide figura 2.

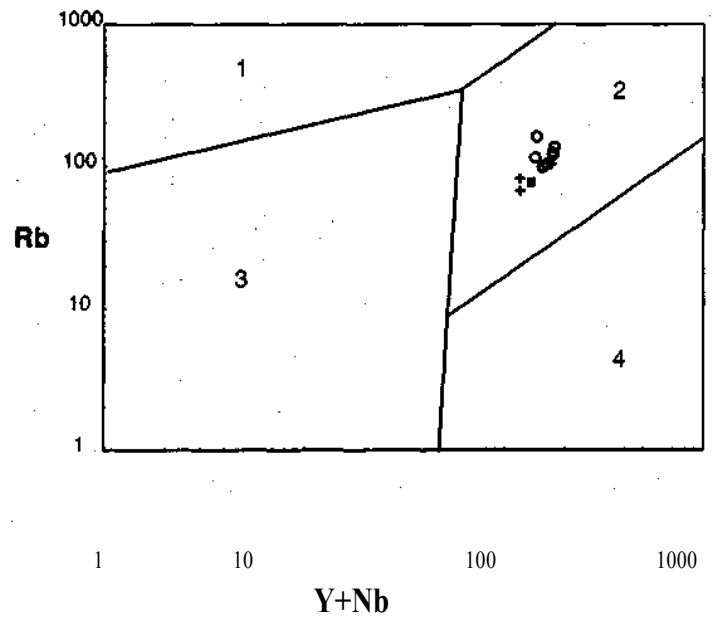

Figura 9 - Diagrama discriminante de ambiente tectônico (Pearce et al. 1984). Símbolos como na figura 2. Legenda: $l=$ granitos sin-colisionais; 2 = granitos intraplaca; 3 = granitos de arcos vulcânicos; 4 = granitos de cadeia meso-oceânica.

riolíticas. Foi estabelecido para o líquido parental a mesma composição utilizada como líquido final no primeiro teste. Para o líquido final do segundo teste, foi adotado uma composição riolítica média com teores de sílica superiores a $75 \%$. De acordo com este modelamento os riólitos altasílica (> 75\% SiOi) podem ter sido gerados pela cristalização de $27 \%$ do líquido riolítico inicial, com a extração de $35 \%$ de plagioclásio (Anio), $54 \%$ de feldspato alcalino e $11 \%$ de magnetita.

estes com elementos-traço (Clarke 1990) são apresentados na Tabela 4. Os resultados obtidos são satisfatórios e permitem considerar a hipótese de cristalização fracionada, conforme sugerido pelo modelamento com elementos maiores. As diferenças entre os dados calculados e os obtidos para os riólitos podem ser explicadas pela variação dos valores dos coeficientes de partição. O conteúdo de elementostraço observados na composição riolítica alta-sílica estão mais afastados daqueles calculados pelo programa, porém dentro dos intervalos de Kds apresentados por Henderson (1984). As maiores diferenças encontram-se entre os valores calculados e obtidos para $\mathrm{Ba}$ e $\mathrm{Sr}$. Mahood \& Stimac (1990) constataram que o comportamento destes elementos pode variar de fortemente compatível a fracamente compatível com o aumento da alcalinidade em magmas alta sílica. Este fato pode explicar os maiores conteúdos de $\mathrm{Ba}$ e $\mathrm{Sr}$ em suítes comendíticas, 


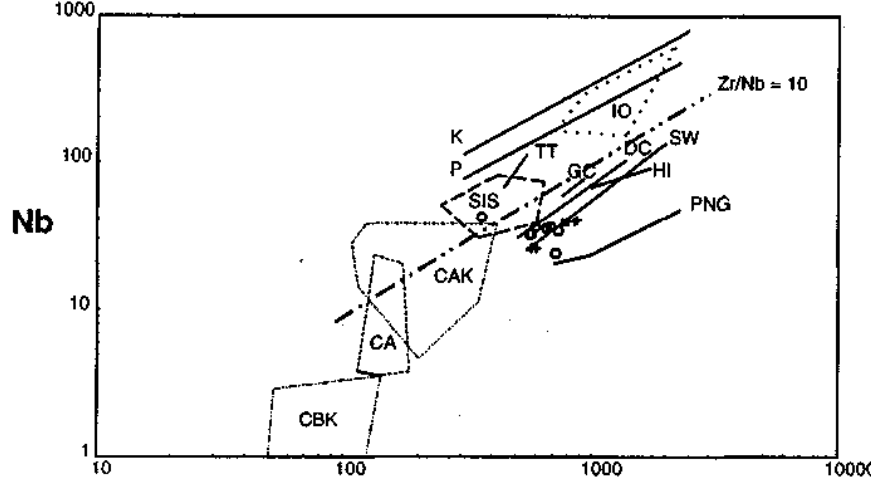

$\mathbf{Z r}$

Figura 10 - Amostras da SVA plotadas no diagrama discriminante de ambiente tectônico, segundo Leat et al. (1986). Símbolos conforme figura 2; Legenda: SIS = campo ocupado por amostras do pertita granito do Complexo Granítico de Lavras do Sul e granito peralcalino de Dom Perdito, vinculados à Suite Intrusiva Saibro (a partir de Gastai et al. 1992); $S W=$ Snowdow Rhyolites; $C B K=$ cálcio-alcalino baixo potássio; $C A=$ cálcio-alcalino; $C A K=$ cálcio-alcalino alto potássio; $P N G=$ Papua Nova Guiné; $H l=$ Major Island; $D C=$ Devine Canyon Tuff; $G C=$ Grouse Canyon Tuff; $T T=$ Tala Tuff; $P=$ Pantelleria; $K=$

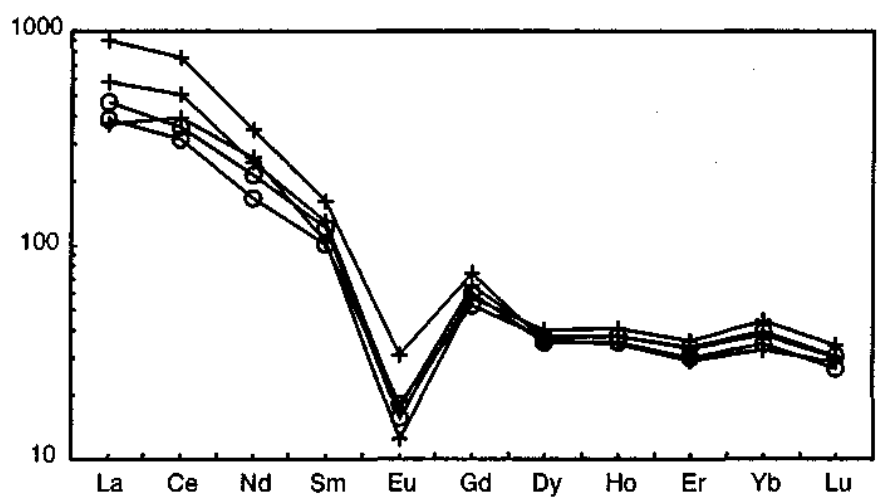

Figura 11 - Variação no conteúdo de REE da SVA, normalizadas ao condrito de Haskin (Haskin et al. 1968). Símbolos: vide figura 2.

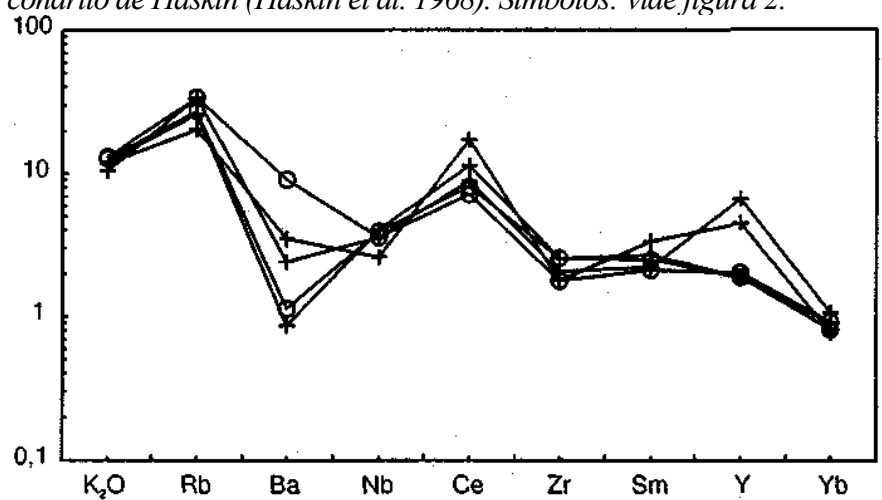

Kilombe, Kenya; $I O=$ Ilhas oceânicas.

Figura 12 - Diagrama multi-elementar mostrando o comportamento de alguns elementos traços e terras raras em amostras da $\boldsymbol{S} \boldsymbol{V A}$, normalizados segundo os valores do ORG de Pearce et al (1984). Símbolos: vide figura 2.

como a SVA, diferente de riólitos alta sílica de natureza sub-alcalina, onde são esperados coeficientes de partição bem mais elevados. Tais diferenças de compatibilidade pode ser também considerada para explicar o comportamento do Rb no primeiro teste, onde observou-se valores superiores aos calculados. Em magmas peralcalinos este elemento mostra-se menos compatível que nos termos metaluminosos (Drexler et al 1983).

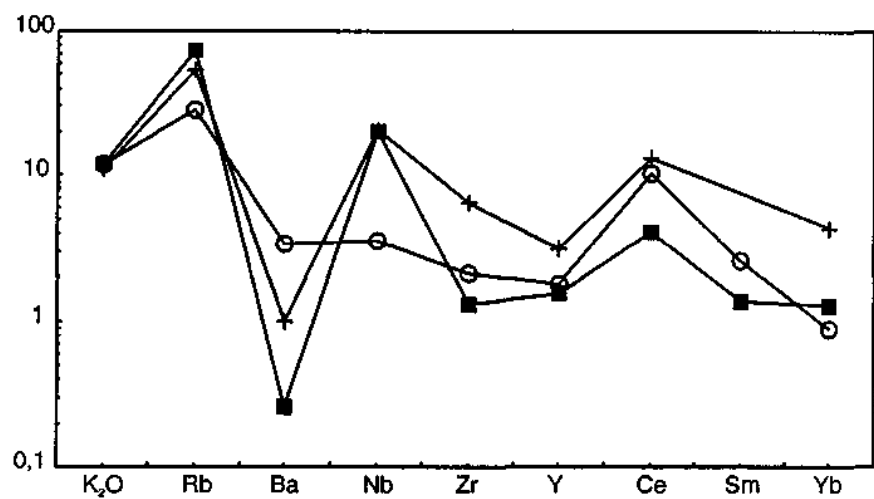

Figura 13 - Diagrama multi-elementar mostrando o comportamento médio de alguns elementos traços e terras raras da SVA, em comparação a outras suites alcalinas. Legenda: $O=-$ composição média da SVA; - composição média de riólitos alcalinos anorogênicos: Kenya Rift (MacDonald et al. 1987); + = composição média de pantelleritos: Pantellería (Villari 1974).

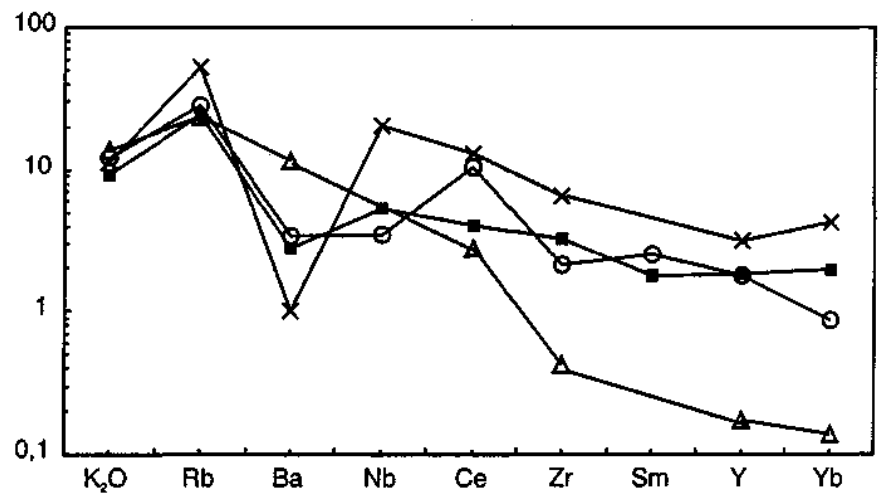

Figura 14 - Diagrama multi-elementar comparando a composição média da $\boldsymbol{S V A}$ e a composição de riólitos alcalinos pós-orogênicos, anorogênicos e cálcio-alcalinos. Legenda: $O=$ composição média da $\boldsymbol{S V A} ; X=$ riólitos anorogênicos (pantelleritos - Pantelería, Villari 1974); - = riólitos alcalinos pós-orogênicos (Snowdonia - Leat et al 1986); $\Delta$ = riólitos cálcio-alcalinos (Bishop Tuff- Hildreth 1981).

$\mathrm{Nb}$ e o Y também mostraram diferenças entre os valores calculados e os obtidos. Os conteúdos destes elementos entre as rochas riolíticas da SVA permaneceram praticamente inalterados. Tal comportamento tem sido também observado por Gastai \& associados a este vulcanismo.

Os resultados obtidos pelo modelamento Nardi (1992) nos granitos alcalinos metaluminosos e testes com elementos-traço permitem sugerir uma hipótese de evolução do magmatismo ácido alcalino do Platô do Taquarembó, a partir da evolução de líquidos básicos moderadamente alcalinos, seguido de dois estágios magmáti-cos envolvendo principalmente mecanismos de cristalização fracionada, não sendo descartada a possibilidade de assimilação crustal em pequenas percentagens (AFC).

CONSIDERAÇÕES FINAIS O vulcanismo ácido alcalino na porção sul do Platô do Taquarembó é representado por uma sucessão de rochas efusivas, piroclásticas e vulcanoclásticas. De acordo com a sucessão de eventos, o vulcanismo da SVA pode ser separado em dois episódios principais: episódio dominantemente efusivo e episódio dominantemente explosivo. O episódio efusivo é responsável pela extrusão de lavas de composição traquítica à riolítica, enquanto que o episódio explosivo foi responsável principalmente pela geração de depósitos de fluxo piroclástico do tipo ignimbrítico. As várias características observadas nas diferentes litologias da SVA, permitem caracterizá-la como de natureza subaérea, comum em ambientes continentais pós-orogênicos.

O comportamento dos elementos maiores, traço e ETR permite classificar o magmatismo responsável pela formação da SVA, como de natureza ácida e caráter comendítico, semelhante aos sistemas de 
Tabela 3 - Cálculos de balanço de massas para elementos maiores, baseado em Stormer \& Nicholls 1978. Composição das fases minerais: plagioclásio $\left(A n_{40}\right.$ e $\left.A n_{20}\right)$, feldspato alcalino: dados obtidos de Stormer \& Nicholls 1978; clinopiroxênio (hedembergita): dados obtidos a partir de Deer et al. 1966; magnetita: dados obtidos a partir de DaWAgnol et al. 1997. Valores do líquido e dos minerais em \% por peso. Teste 1: Diferenciação de um líquido riolítico $\left(69-74 \% \mathrm{SiO}_{2}\right)$ a partir de um líquido traquítico $\left(64-69 \% \mathrm{SiO}_{2}\right)$. LO = média das amostras CC-45B, CC-194, CC-45A, CC-06A e CC-133; L1 = média das amostras CC-79, CC-69, CC-65', CC-65, CC-69C, CC-19. Teste2: diferenciação de um líquido riolítico (> 75\% de sílica), a partir de um líquido parental com teores de sílica variando entre 69 e 74\%. LO= idêntico a L1 do teste 1; $\mathbf{L 1}=$ média das amostras CC-41 e CC-41'.

\begin{tabular}{|c|c|c|c|c|c|c|c|c|}
\hline & \multicolumn{8}{|c|}{ TESTE 1} \\
\hline & $\begin{array}{l}\text { Ligumo } \\
\text { INISARL } \\
\text { (t:0) }\end{array}$ & And & $C_{p p}$ (Wredembergilus) & Mingenting & $\begin{array}{l}\text { Feldeppata } \\
\text { Alestinul }\end{array}$ & $\begin{array}{l}\text { Liqumo } \\
\text { FiNAL (L) }\end{array}$ & CAtCULADO (LI") & 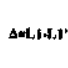 \\
\hline sio, & 68.37 & 57,98 & 49.29 & - & 64.90 & 7321 & 73.05 & 0.16 \\
\hline $\mathrm{M}_{p} \mathrm{O}_{1}$ & 13.26 & 26,39 & 0.31 & 0,05 & 12.59 & 12.25 & $\$ 2.05$ & 0,20 \\
\hline $\mathrm{Fe}_{1} \mathrm{O}_{*}$ & 6,43 & 0.21 & 27,48 & 92.03 & 0.34 & 4.17 & 4.02 & 0.15 \\
\hline Mro & 0.45 & 0.03 & 1.08 & - & . & 0.38 & 0.52 & -0.14 \\
\hline$c * 0$ & 1.45 & 7.82 & 21.68 & - & 0.48 & 0.42 & 0.36 & 0,06 \\
\hline $\mathrm{Na}_{20} \mathrm{O}$ & 4.60 & 8,47 & 0.14 & . & $2 \pi$ & 4,46 & $4 . \%$ & .0 .30 \\
\hline$K_{0}, 0$ & 4.80 & 1.10 & n.03 & . & 11.91 & 4.83 & 4.87 & 0,04 \\
\hline \multirow[t]{5}{*}{ no $_{i}$} & 0.55 & . & 0.08 & 1.79 & . & 0.29 & $0.5 \%$ & $-0,27$ \\
\hline & \multicolumn{5}{|c|}{ SOMA DOS QUAMRAMDOS DO RESSIDUOS: 0,27} & \multicolumn{3}{|c|}{ TOTAL, FRACHNABO: 25,77\% } \\
\hline & \multicolumn{8}{|c|}{ 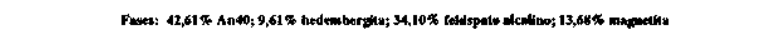 } \\
\hline & \multicolumn{8}{|c|}{ TESTE 2} \\
\hline & Llou & & Amaso & Mwgreat: & Nothopute & $\begin{array}{l}\text { Lloumo } \\
\text { PTAMLL (L) }\end{array}$ & $\begin{array}{l}\text { I.GUDOO EJMAL } \\
\text { CALCULADO (LA') }\end{array}$ & $\Delta=1.1 .11^{\circ}$ \\
\hline $\mathrm{sol}_{2}$ & 73 & & 60.36 & . & 64.90 & 79.79 & 79,66 & 0,13 \\
\hline $\mathrm{AH}_{\mathrm{z}} \mathrm{O}_{\mathrm{H}}$ & 12. & & 22.89 & 0,05 & 19.59 & 10,10 & 9,83 & 0.28 \\
\hline $\operatorname{lig}_{8} 0, *$ & 4.1 & & 0.09 & 92,03 & 0.34 & 1.84 & 1.79 & 0.12 \\
\hline $\mathbf{M}_{\mathbf{E}} \mathbf{O}$ & & & 0.03 & . & . & 0,30 & 0.47 & $-8,17$ \\
\hline 60 & a. & & 4.99 & . & 0.48 & 0.16 & osn & 0.17 \\
\hline$N, 0$ & 4. & & 8,99 & - & 277 & $\$ .75$ & 4.22 & 0.47 \\
\hline $\boldsymbol{K}_{i} \mathrm{O}$ & 4.8 & & 0.05 & & $1+\$ 9$ & $\$, 8 \pm$ & 4,02 & a, id \\
\hline \multirow[t]{3}{*}{$11 \mathrm{O}_{2}$} & 0.2 & & 0,01 & 1.75 & . & 0,1 a & 0.78 & 0,11 \\
\hline & \multicolumn{5}{|c|}{ SOMA DOS QUADRADOS DOS RESDUCS: 0,42} & \multicolumn{2}{|c|}{ 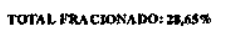 } & \\
\hline & & & 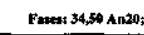 & 1; 34,45\% ret & 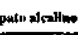 & : 11,11 : & & \\
\hline
\end{tabular}

alta sílica. A afinidade alcalina deste magmatismo fica evidenciada pelos elevados teores de $\mathrm{Na}_{2} \mathrm{O}, \mathrm{K}_{2} \mathrm{O}, \mathrm{HSFE}$, ETR leves, $\mathrm{FeO}_{\mathrm{t}} / \mathrm{FeO}_{\mathrm{t}}+\mathrm{MgO}$ e índice agpaítico próximo a unidade. No diagrama $\mathrm{Na}_{2} \mathrm{O}+\mathrm{K}_{2} \mathrm{O}$ x $\mathrm{Al}_{2} \mathrm{O}_{3}$ (molar) a maior parte das amostras ocupam o campo peralcalino, o que é coerente com a presença de anfibólios alcalinos nestes vulcanitos.

A evolução geoquímica do magmatismo ácido alcalino da SVA pode ser explicada por processos de cristalização fracionada associada, possivelmente, a mecanismos de assimilação crustal (AFC). Esta evolução foi testada através do balanço de massas, apresentando resultados matematicamente satisfatórios e coerentes com os dados petrográfícos. Sugere-se, desta forma, que as rochas riolíticas podem ter sido originadas a partir da cristalização fracionada de líquidos traquíticos, envolvendo o fracionamento de plagioclásio, feldspato alcalino, piroxênio e magnetita. Apesar da ausência de rochas básicas nesta sequência, sugere-se que as rochas traquíticas tenham sido
Tabela 4 - Hipótese de cristalização fracionada testada através do modelamento de elementos traço, utilizando-se o programa NEWPET (Clarke 1990). A proporção de líquido remanescente (F), bem como das fases minerais utilizadas foram obtidas a partir do modelamento de elementos maiores. Os valores apresentados estão emppm. Teste 1: intervalo identico ao apresentado no teste l da tabela 3. Teste 2: intervalo idêntico ao apresentado no teste 2 da tabela 3.

\begin{tabular}{|c|c|c|c|c|c|c|c|c|c|c|c|}
\hline \multicolumn{6}{|c|}{ Teste 1} & \multicolumn{6}{|c|}{ Teste 2} \\
\hline \multirow{2}{*}{\multicolumn{3}{|c|}{$\begin{array}{c}\text { Concentracio } \\
\text { [nicial do Liquido } \\
\text { (C.) } \\
R \mathrm{~b}=70,00 \\
\mathrm{~S} r=73,60 \\
\mathrm{Ba}=174,40 \\
\mathrm{Z}_{\mathrm{r}}=599,40 \\
\mathrm{r}=93.60\end{array}$}} & \multirow{2}{*}{\multicolumn{3}{|c|}{ 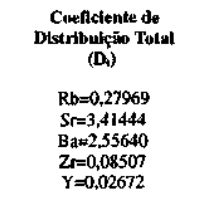 }} & \multirow{2}{*}{\multicolumn{3}{|c|}{ 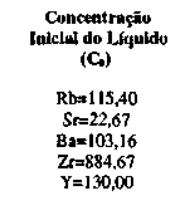 }} & \multirow{2}{*}{\multicolumn{3}{|c|}{ 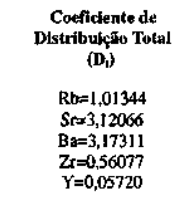 }} \\
\hline & & & & & & & & & & & \\
\hline $\mathbf{F}$ & $\mathbf{R b}$ & Sr & B: & $\mathbf{Z r}$ & $Y$ & $F \%$ & $\mathbf{R b}$ & $\mathbf{S} \mathbf{r}$ & By & $\mathbf{z r}$ & $\mathbf{Y}$ \\
\hline 5 & 77,7 & 0.39 & 13,8 & 1909 & 1407 & 5 & 111 & 0.099 & 0.15 & 3298 & 2191 \\
\hline 10 & 75,8 & 1,32 & 24,9 & 1460 & $7 \$ 2$ & 10 & 112 & 0.17 & 0,69 & 2432 & 1140 \\
\hline 15 & 74,8 & 2,68 & 35.0 & 1248 & 521 & 15 & 112 & 0.41 & 1.67 & 2035 & 778 \\
\hline 20 & $7_{4,0}$ & 4,42 & 447 & 1117 & 402 & 20 & 113 & 0,75 & 3,12 & 1794 & 593 \\
\hline 25 & 73,5 & 6,53 & 54,0 & 1024 & 328 & 25 & 113 & 1,20 & $s_{T} 07$ & 1626 & 480 \\
\hline 30 & 73,0 & 3,98 & 63,0 & 955 & 278 & 30 & 114 & 1,76 & 7.54 & $150]$ & 404 \\
\hline 35 & 72.6 & 11,8 & 71,8 & $89 y$ & 242 & 35 & 114 & 2,45 & $10: 5$ & 1403 & 350 \\
\hline $4 \pi$ & 72.3 & 14,8 & 80,3 & 854 & 214 & 40 & 114 & 3,25 & 14,1 & 1323 & 308 \\
\hline 45 & $\pi 2,0$ & 18.2 & 88.3 & 816 & 193 & 45 & 114 & 4.17 & 18,2 & 1256 & 276 \\
\hline 50 & 71,7 & 21,9 & 97,0 & 784 & 175 & 50 & 114 & 5.21 & 22,9 & 1200 & 250 \\
\hline 55 & 71,5 & 25,9 & 105 & 795 & 161 & S5 & 114 & 6,38 & 28,1 & 150 & 228 \\
\hline 60 & 71,3 & 30,2 & 113 & 730 & 149 & 60 & 115 & 7,67 & 340 & 1107 & 210 \\
\hline 65 & 71,1 & 34.7 & 121 & 708 & 138 & 65 & 115 & 9,09 & 40,5 & 1069 & 19.5 \\
\hline 70 & 70.9 & 39,5 & 129 & 688 & 129 & 70 & 115 & 10,6 & 47,5 & 1035 & 182 \\
\hline 75 & 70.7 & 44,5 & 137 & 670 & 121 & 75 & t15. & 12,3 & 55.2 & 1004 & 171 \\
\hline 80 & 70,5 & 49.8 & 144 & 653 & 115 & 80 & $\$ 15$ & 14,1 & 63,5 & 976 & 160 \\
\hline 85 & 30,4 & 55,4 & 152 & 638 & 108 & 85 & 115 & 16,1 & 72,5 & 950 & 152 \\
\hline 90 & 70,3 & 61,2 & 160 & 624 & 103 & 90 & 115 & 18,1 & 82,0 & 927 & 144 \\
\hline$y 5$ & 70.1 & 67,3 & 167 & 611 & 98,0 & y5 & 115 & 20,3 & 92,3 & 905 & 136 \\
\hline
\end{tabular}

originadas a partir de basaltos transicionais ou moderadamente alcalinos, por processos de AFC.

Nos diagramas discriminantes $\mathrm{Zr} \times \mathrm{Nb}, \mathrm{RI} \times \mathrm{R} 2 \mathrm{e} \mathrm{Y}+\mathrm{Nb} \times \mathrm{Rb}$, as amostras da SVA ocupam o campo das rochas alcalinas de caráter pós-orogênico. Esta mesma afinidade é também sugerida pelo padrão de elementos terras raras. As rochas vulcânicas da SVA marcam provavelmente as últimas manifestações magmáticas relacionadas ao ciclo Brasiliano no Escudo Sul-rio-grandense.

Agradecimentos Ao CPGq-Instituto de Geociências, PRONEX e CNPQ (Projeto Integrado 520036/96) pelo apoio financeiro e facilidades de infra-estrutura e a dois revisores anónimos da RBG pelas sugestões ao texto orginal.
Babinsky, M., Chemale, F.Jr., Hartmann, L.A., Van Schmus, W.R. \& Silva, L.C. 1996. Juvenile accretion at 750-700 Ma southern Brazil. Geology, 24:439-442.

Baker, B.H. \& McBirney, A.R. 1985. Liquid fractionation. Part IIII: Geochemistry of zoned magmas and the compositional effects of liquid fractionation. J Volcanol. Geotherm.Res., 24:55-S1.

Chappel, B.W. \& White, A.J.R. 1992.1- and S-type granites in the Lachan fold belt. Special Paper Geological Society of America, 272:1-26.

Clarke, D. 1990. Newpet: a petrological program. Department of Earth Sciences. Memorial University of Newfoundland., Canadá (inédito).

Dali'Agnol, R., Pichavant, M. \& Champenois, M. 1997. Iron-titanium oxide minerais of the Jamon Granite, eastern amazoniam region, Brazil: implications for the oxygen fugacity in Proterozoic, A-type granites. Acad. Bras.de Ciências, 69(3): 325-347.

Deer, W. A. , Howie, R. A. \& Zussman, J, 1980. An introduction to the wck-forming minerais. London. Longman Group Limited, $528 \mathrm{p}$.

Drexler, J.W., Bornhorst, T.J. and Noble, D.C. 1983. Trace element sanidine/glass distribution coefficients for peralkaline silicic rocks and their implications to peralkaline petrogenesis. Lithos, 16: 265-271

\section{Referências}

Ewart, A. 1979. A review of the mineralogy and chemistry of Tertiary-Recent dacitic, latitic, rhyolitic and related salic volcanic rocks. In F. Baker (ed.) Trondhjemites, dacites and related rocks. The Hague: Elsevier, p. 113-121.

Gastai, M.C.P. \& Nardi, L. V.S. 1992. Petrogenese e evolução do Granito Jaguari: um típico representante metaluminoso da Suíte Intrusiva Alcalina Saibro. Geochimica Brasiliensis, 6(2): 169-189.

Gastai, M.C.P. Schmitt, R.S. \& Nardi, L.V.S. 1992. Granitóides da parte centro-sudoeste do Escudo Sul-rio-grandense: Novos dados e discussão sobre a génese e tipologia do magmatismo alcalino. Pesquisas, 19(2): 174-182.

Haskin, L.A., Haskin, M.A., Frey, F.A. and Wildeman, T.R. 1968. Relative and absolute terrestrial abundances of the rare earths. In: Archeans, L.H. (ed.) Origin and distrihution ofthe elements. Oxford, Pergamon. P. 889-912.

Henderson, P. 1984. Inorganic Geochemistry. New York. Pergamon Press. 353 p.

Hildreth, W. 1981. Gradients in silicic magma chambers: implications for lithospheric magmatism. J. Geophys. Res., 86: 10153-10192.

Kraemer, G. 1995. Evolução magmática e tectônica da Suíte Ortometamórftca Imbicuí, região de Lavras do Sul (RS). Dissertação de Mestrado, Universidade Federal do Rio Grande do Sul. Porto Alegre, Brasil, 99 p. 
Leat, P.T.; Jackson, S.E., Thorpe, R.S. \& Stillman, C.J. 1986. Geochemistry of bimodal basalt -subalkaline/peralkaline rhyolite provinces within the Southern British Caledonides. J. Geol. Society, London, 143: 259-273.

Le Bas, M.J., Lê Maitre, R.W., Streckeisen, A. \& Zanettin, B. 1986. A classification of volcanic rocks based on the total alcalis-silica diagram. J. Petrol., 27:745-750.

Leite, J.A.D. 1995. Datação Shrimp U/Pb em zircões e o exemplo de dois corpos graníticos contrastantes no Escudo Sul-Rio-grandense. In: SBG/Núcleo RS, 6 _impósio Sul-Brasileiro de Geologia, Resumos expandidos, 5-12

MacDonald, R. 1974. Nomenclature and Petrochemistry of the Peralkaline Oversaturated Extrusive Rocks. Bulletin Volcanologique, 38: 498 - 516.

MacDonald, R.; Davies, G.R.; Bliss, C.M.; Leat, P.T.; Bailey, D.K. \& Smith, R.L. 1987. Geochemistry of Higfcsilica Peralkaline Rhyolites, Naivasha, Kenya Rift Valley. Journal of Petwlogy, 28(6) 979-1008.

Mahood,G.A.\& Hildreth.W. 1983. Nested calderas and trapdoor uplift at Pantelleria, Strait of Sicily. Geology,II: 722-726

Mahood, G.A. \& Stimac, J.A. 1990. Trace-element partitioning in pantellerites and trachytes. Geochimica and Cosmochimica Acta, 54: 2257-2276.

Maniar, P.D. \& Piccoli, P.M. 1989. Tectonic discrimination of granitoids. Geological Society of America Bulletin, 101: 635-643.

Metz, J.M. \& Mahood, G.A. 1991 Development of the Long Valley, Calofornia, magma chamber record in precaldera rhyolite lavas of glass Mountain. Contributions to Mineralogy and Petrology, 106(3): 379-397.

Nardi, L.V.S. 1991. Caracterização petrográfica e geoquímica dos granitos mataluminosos da associação alcalina: revisão. Pesquisas, 18(1): 44-57.

Nardi, L.V.S. \& Bonin, B. 1991. Post-orogenic and non-orogenic alkaline granite associations: the Saibro intrusive suite, southern Brazil -A case study. Chem. Geol. 92: 197-212. Nardi, L.V.S. \& Hartmann, L.A. 1979. O Complexo Granulítico Santa Maria Chico do Escudo Sul-riograndense. Acta Geológica Leopoldensia, 3 (6): 45-76. Nardi, L.V.S.

\& Lima, E.F. 1998. Hybridization of mafic microgranular enclaves in the Lavras Granite Complex, RS, Brazil. Journal of South American Earth Sciences (no prelo).

Paim, P.S.G., Lopes, R.C. \&Chemale Jr, F. 1995. Aloestratigrafia, sistemas deposicionais e evolução paleogeográfica da Bacia do Camaquã - Vendiano Superior/ Ordoviciano Inferior do RS. SBG/Núcleo RS, Simpósio Sul-Brasileiro de Geologia, Resumos expandidos, 39-50.

Pearce, J.A.; Harris, N.B.W.; Tindle, A.G. 1984. Trace element discrimination diagrams for the tectonic interpretation of granitic rocks. Journal of Petrology, 25(4): 956-983.
Ribeiro, M. \& Fantinel, L.M. 1978. Síntese da geologia do Rio Grande do Sul. In: XXX Congresso Brasileiro de Geologia, Recife, Anais. 6: 2451-2464.

Sommer, C. A. 1994.0 vulcanismo ácido alcalino da porção sul do Platô do Taquarembó, Dom Pedrito, RS. Dissertação de Mestrado, Universidade Federal do Rio Grande do Sul. Porto Alegre, Brasil, 149 p.

Stormer, J.C. \& Nicholls, J. 1978 - XLFRAC: a program for the interactive testing of magmatic, differentiation models. Computer Geosci. 4: 143-159.

Turner, S.P., Foden, J.D. and Morrison, R.S. 1992. Derivation of some A-type magmas by fractionation of basaltic magma: An example from the Padthway Ridge, South Austrália. Uthos, 28: 151-179.

Villari, L. 1974. The island of Pantelleria. Buli. Volcanol, 38: 689-724. Watson, E.B. 1979.

Zircon saturation in felsic liquids: experimental data and applications to trace element geochemistry. Contributions to Mineralogy and Petrology. 70: 407-419.

Watson, E.B. and Harrison, T.M. 1983. Zircon saturation revisited: temperature and composition effects in a variety of crustal magma types. Earth and Planetary Science Letters, 64: 295-304.

Westrich, H.R., Stockman, H.W. and Eichelberger, J.C. 1988. Degassing of rhyolitic magma during ascent and emplacement. Journal of Geophysical Research, 93 (36): 6503-6511.

Whalen, J.B., Currie, K.L. and Chappell, B.W. 1987. A-type granites: geochemical characteristics, discrimination and petrogenesis. Contibutions to Mineralogy and Petrology. 87: 319-327.

White, C.M. 1992 Evolution of calc-alkaline magmas at the early Quaternary Battle Ax Volcano, Western Cascade Range, Oregon. Journal of Volcanology and Geothermal Research, 54(1-3): 107-122.

Wilson, M. 1993. Magmatic Differentiation. /. Geol. Soe. London. 150 (4): 611-624.

Wilson, M. 1989. Igneous Petrogenesis. Londres, Unwin Hyman. 466p.

Winchester, J. A. \& Floyd, P.A. 1977. Geochemical discrimination of different magma series and their differentiation products using immobile elements. Chem. Geol., 20: 325-343.

Manuscrito A-1032

Recebido em 5 de setembro de 1998

Revisão dos autores em 10 de fevereiro de 1999 Revisão aceita em 15 de fevereiro de 1999 